\title{
Tendencias en la demanda laboral del sector turístico del Ecuador
}

\section{Labor demand trends in tourist sector of Ecuador}

\author{
Enrique Cabanilla Vásconez \\ ${ }^{1}$ Universidad Central del Ecuador. Facultad de Ciencias Agrícolas. Carrera de Turismo Ecológico. \\ Jerónimo Leiton y Av. La Gasca s/n. Ciudadela Universitaria. Quito. 170521. Ecuador
}

\begin{abstract}
Resumen
El presente artículo busca determinar la demanda laboral no satisfecha de personal calificado en el sector turístico del Ecuador. La investigación tiene dos partes, una a partir de los datos estadísticos comparativos del Ecuador con mercados competidores, mediante lo cual se establece el posible desarrollo del turismo en el país para fundamentar la necesidad de una masa crítica de personal profesionalizado al más alto nivel, y en segundo lugar, con los datos laborales obtenidos de entrevistas a expertos y a noticias del Ministerio de Turismo, con los que se determinó que la brecha entre el personal formado y disponible con la demanda laboral real existente en el país es significativa.
\end{abstract}

Palabras clave: personal turismo, tendencias turismo, turismo Ecuador.

\begin{abstract}
This article seeks to determine unmet labor demand of qualified personnel in the tourist sector of Ecuador. The research has two parts, one from the comparative statistics of Ecuador with competitive markets whereby the possible development of tourism in the country is set to support the need for a critical mass of professionalized staff at the highest level, and Secondly, the employment data obtained from interviews with experts and news from the Ministry of Tourism, with which it was determined that the gap between staff trained and available to existing real labor demand in the country is significant.
\end{abstract}

Keywords: tourism staff, tourism trends, tourism Ecuador.

\section{La actualidad del sector turístico en Ecuador}

De acuerdo con el Plan de Desarrollo Turístico (PLANDETUR 2020), Ecuador busca desarrollar un turismo sostenible que genere beneficios directos en los lugares en los cuales esta actividad se lleva a cabo, mediante la generación de empleo directo, la gestión de los servicios turísticos y el fortalecimiento de la cadena de producción local. Esto requiere la participación de todos los interesados en la construcción de un sistema inclusivo, solidario y respetuoso, con especial cuidado de los recursos naturales y culturales del país. Al mismo tiempo, el turismo es considerado como una alternativa para el alivio de la pobreza, con la participa- ción de poblaciones que deciden aventurarse en el llamado turismo comunitario (Ministerio de Turismo del Ecuador, 2007).

Para lograr estos objetivos, el Plan recomienda varias acciones destinadas a mejorar aspectos como la gobernanza; la descentralización del turismo; la coordinación con otros ministerios para el pleno desarrollo del concepto de la sostenibilidad; el desarrollo de normas de funcionamiento de todos los servicios y arreglos turísticos; construir una seguridad turística programada a nivel nacional; la formación continua de los trabajadores en esta actividad, entre otros.

Según el último Plan de Marketing Turístico Nacional (2011), Ecuador tiene grandes poten- 
ciales al ofrecer productos relacionados con sol y playa, turismo comunitario, parques temáticos, el ecoturismo y el turismo de naturaleza, el deporte y el turismo de aventura, turismo de salud, cruceros, el agroturismo, el sector de reuniones, incentivos, convenciones y exposiciones, todos ellos ubicados en diferentes partes de los llamados Cuatro Mundos de Ecuador, que son: Galápagos, Andes, Costa y Amazonía. Este plan busca posicionar tres características importantes: en primer lugar, para ser el país más megadiverso del mundo de acuerdo con su extensión territorial; en segundo lugar, para ser reconocido como la mitad del mundo; y, por último, ser un líder en la implementación de políticas que fortalezcan sus recursos naturales, culturales y económicos. Es un país que tiene como política de Estado el derecho a la buena vida para todos los que viven en él o lo visitan.
Según estos planes, los diez países con mayor número de acciones promocionales del turismo en Ecuador son: Estados Unidos, Colombia, Perú, España, Alemania, Reino Unido, Canadá, Francia, Argentina, Italia y Brasil. El turismo que genera la mayor parte de la demanda internacional está relacionado con la cultura, el ecoturismo y la aventura. Y, finalmente, los productos turísticos que se encuentran en consolidación están relacionados con el turismo comunitario, el turismo de congresos y convenciones y el turismo de cruceros.

Actualmente, el país está promoviendo una nueva campaña de marketing llamada Todo lo que necesitas es Ecuador (All you need is Ecuador) (Figura 1), que se ejecuta en diferentes ciudades de todo el mundo y ha logrado un buen ranking en Internet. Su marca oficial es Ecuador, ama la vida (Ecuador, love life).

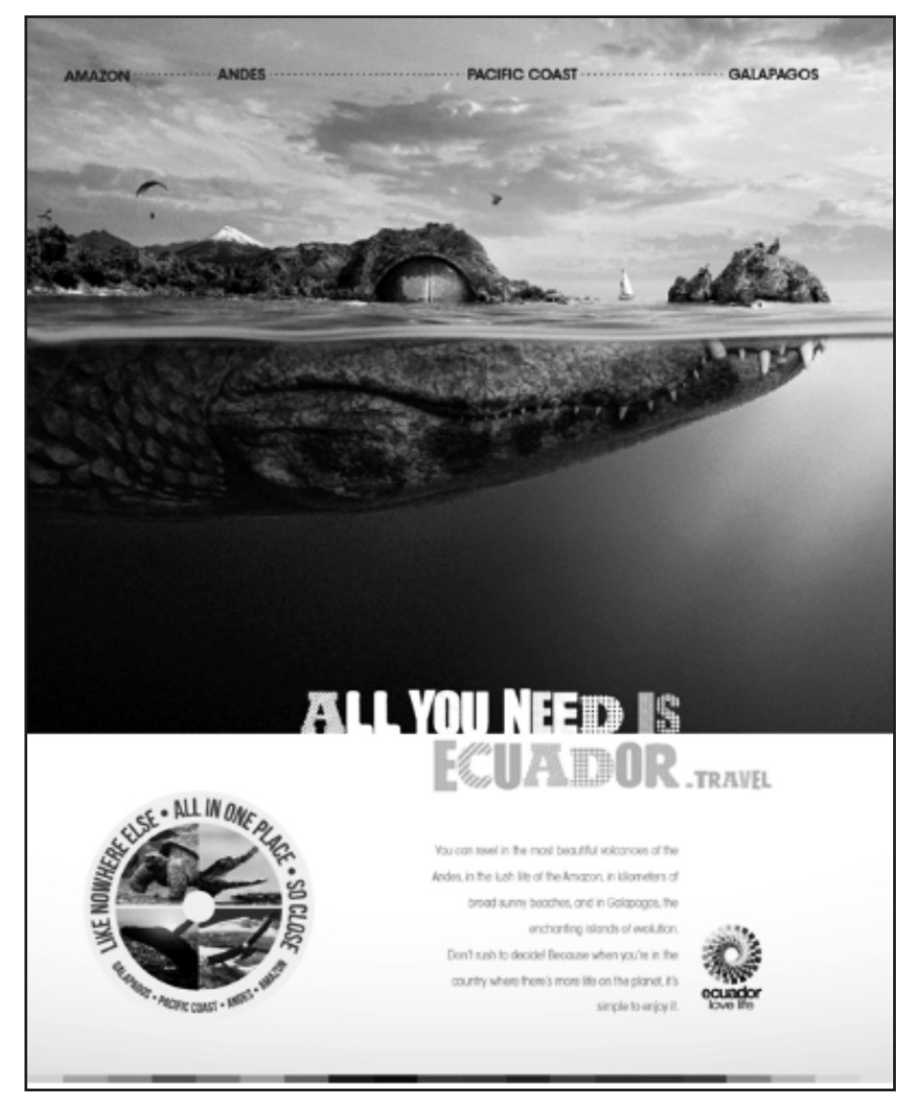

Figura 1. Eslogan y marca país del turismo en Ecuador al 2014. (Ministerio de Turismo, 2014).

\section{Metodología}

La presente investigación es descriptiva-analítica. Descriptiva en cuanto configura la situación actual del turismo en el Ecuador y con base en ello realiza proyecciones a largo plazo. Estos resultados dan paso a un estudio analítico sobre la demanda de talento humano que tendrá el sector en los próximos 
20 años. El método utilizado es mixto: cuantitativo para la utilización y procesamiento de estadísticas, y cualitativo en la interpretación de resultados y entrevistas con expertos calificados del sector.

\section{Resultados}

\subsection{Demanda laboral de acuerdo con la evolución} del turismo ecuatoriano en los últimos 15 años y su proyección al 2035, de forma comparada a sus principales y más directos competidores.

A continuación se presentan las evaluaciones del desarrollo del turismo ecuatoriano en los últimos 15 años, comparado con países que claramente se identifican como competencia directa, que son: Colombia y Perú, como mercados fronterizos, y Costa Rica como un país con oferta similar. Los datos fina- les confirmados y utilizados para esta comparación corresponden a los años 2001 al 2013.

\subsubsection{Proyecciones de la demanda laboral de acuer- do con el número de arribos al país.}

En la Figura 2 se observa la evolución del número de arribos de turistas a los países antes mencionados. Tal como se puede observar al 2001, año base de la comparación, los países iniciaron muy cercanos entre sí. Costa Rica mantenía un liderato en la región, debido en mucho a su posicionamiento como un destino verde y de aventura. Colombia, a la par de Ecuador y Perú muy cerca, sin una brecha significativa, consolidándose como un destino emergente luego de un largo período convulsionado por temas armados de carácter interno y externo. El mercado consolidado a este año base presenta los datos incluidos en la Figura 3.

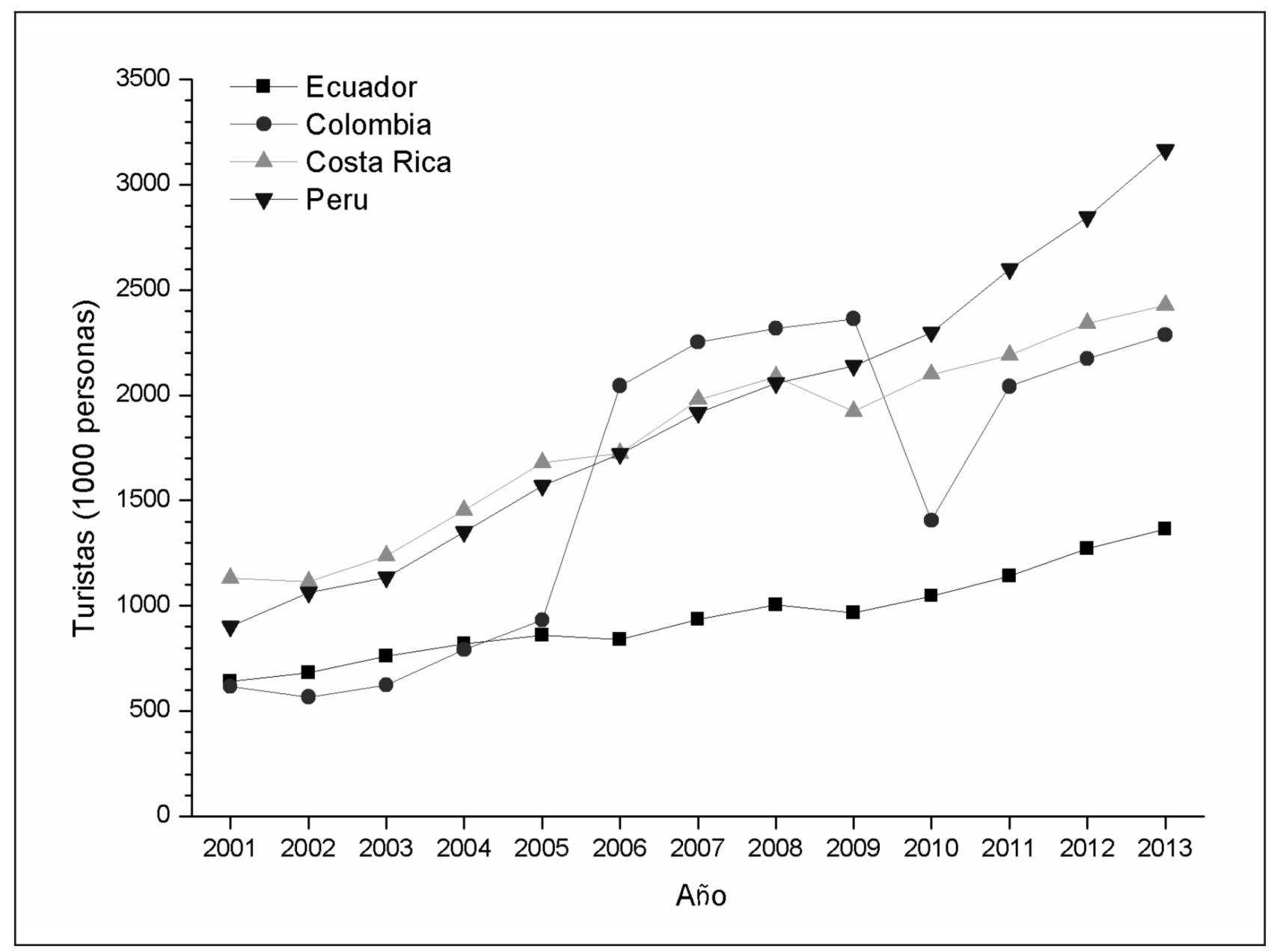

Figura 2. Comparación del número de ingresos de turistas con países competencia de Ecuador. (Fuente: World Development Indicators, 2015). 


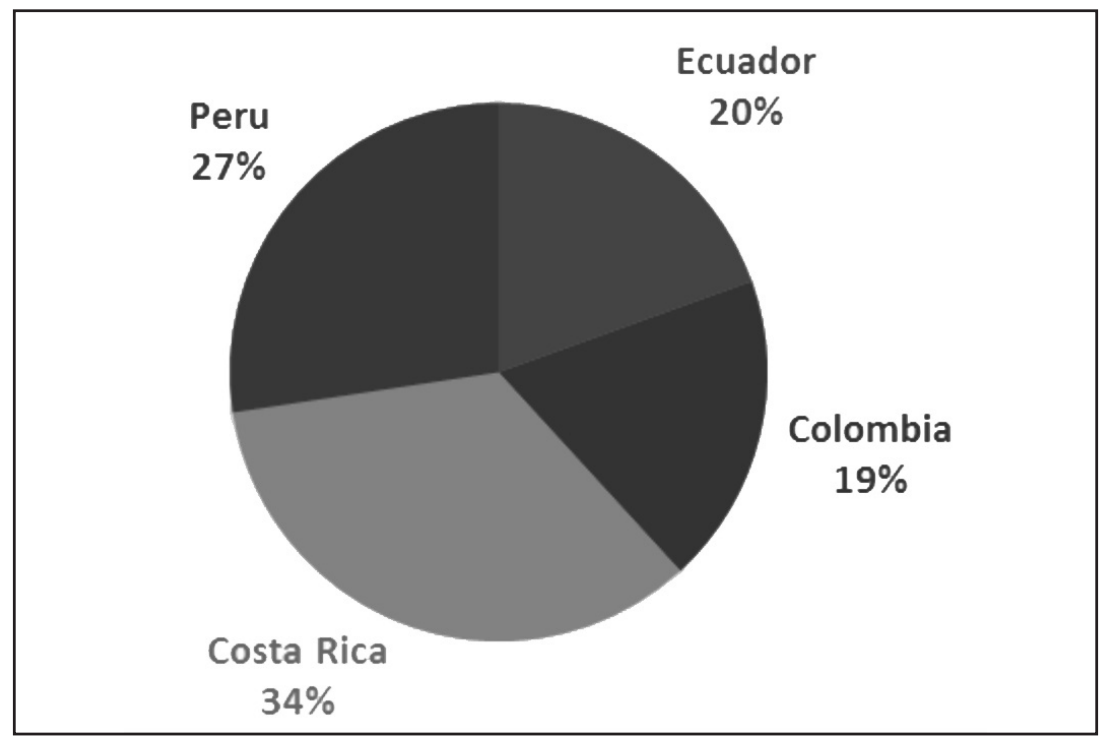

Figura 3. Market share del turismo receptivo en Ecuador comparado con países competencia al 2001. (Fuente: World Development Indicators, 2015).

Aportando al análisis final, el mercado estaba mejor distribuido y las brechas no eran, porcentualmente, significativas. Posteriormente, mientras que Perú y Costa Rica tienen un ascenso notable, con una alta tasa de crecimiento sostenida, Colombia, que estaba a la par de Ecuador, tiene un salto positivo para el 2005, marcando de esta forma una línea de crecimiento que marca una brecha con Ecuador. Si bien Colombia para el 2009 sufre una desaceleración notable, en el 2010 recupera su crecimiento positivo.
De la comparación de la situación del mercado se desprende que Costa Rica y Ecuador pierden varios puntos porcentuales sobre el flujo consolidado de turismo receptivo en esta selección. Perú gana 7 puntos porcentuales y Colombia gana 6 . Se observa claramente que el país está rezagado en su crecimiento y ha perdido su posicionamiento frente al año base, Figura 4).

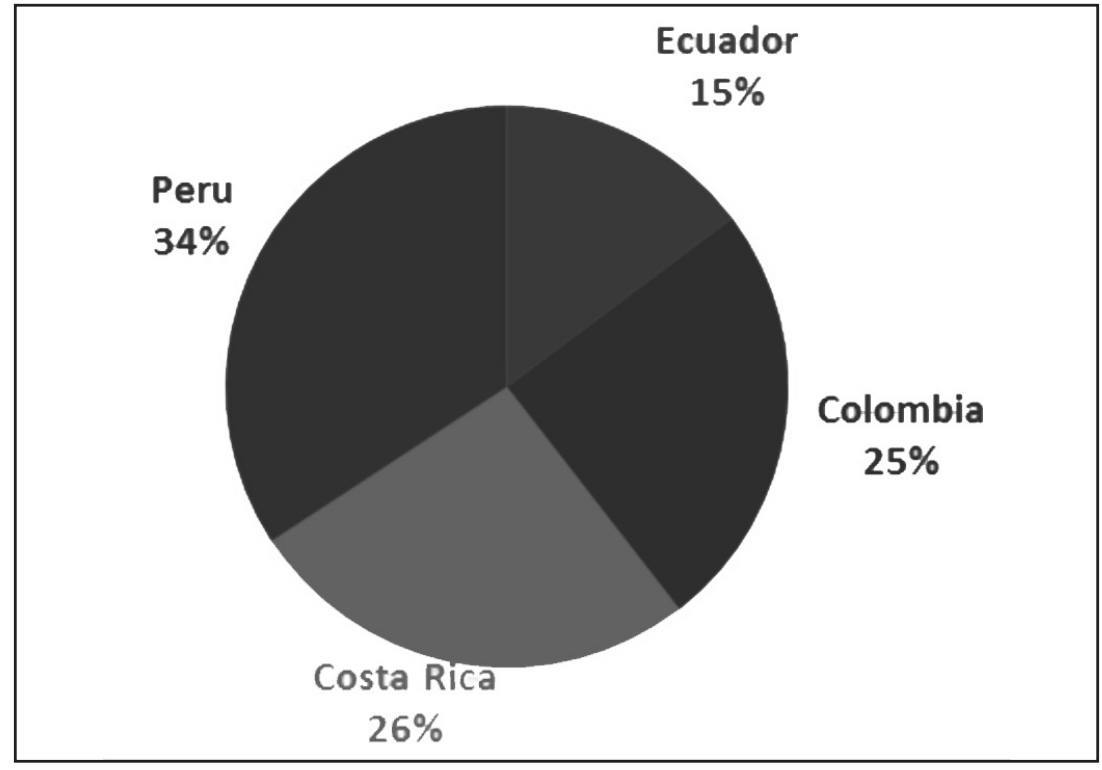

Figura 4. Market share del turismo receptivo en Ecuador comparado con países competencia al 2013. (Fuente: World Development Indicators, 2015). 
Se observa que Ecuador pierde posición de mercado en los últimos 15 años, mientras que los países fronterizos han tenido un desarrollo más relevante y sostenido. Pese a crecer, en varios años sobre su media móvil, la brecha, entre los países comparados según este indicador con Ecuador, ha ido incrementándose.

\subsubsection{Tendencias sobre número de arribos al} 2035 y su incidencia sobre la demanda del talento humano
En base a la media anual de la serie obtenida se ha proyectado el siguiente crecimiento para el Ecuador hasta el año 2035, Figura 5. La media de crecimiento anual es del $6,60 \%$, superior a la media anual a nivel mundial. Hasta el 2035 el número de turistas se habrá cuatriplicado, por lo que el número de profesionales necesarios para planificación, organización, operación y evaluación de este sector productivo tendrá una demanda exponencial significativa.

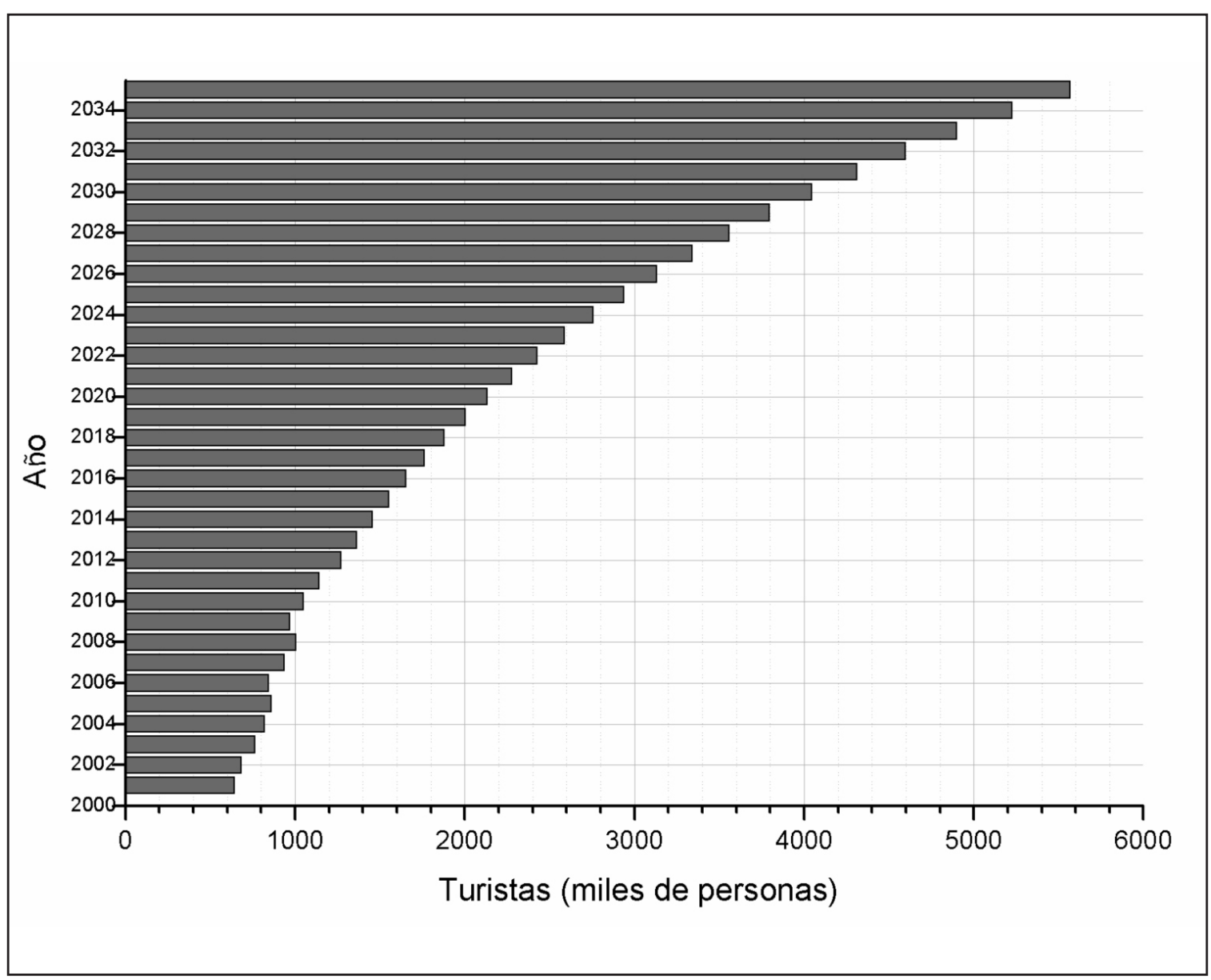

Figura 5. Proyecciones al 2035 del crecimiento del turismo receptivo en Ecuador, en número de personas. (Fuente: World Development Indicators, 2015).

\subsection{Proyecciones de la demanda laboral de acuerdo con los ingresos económicos por turismo}

El turismo ha representado en los últimos años un importante rubro en el Producto Interno Bruto (PIB) del país, manteniéndose siempre entre los primeros cinco puestos, razón por la cual es actualmente considerado como un sector clave para el cambio de la matriz productiva. A continuación se observa la serie con los ingresos en millones de dólares obtenidos por la gestión turística del país (Figura 6). 


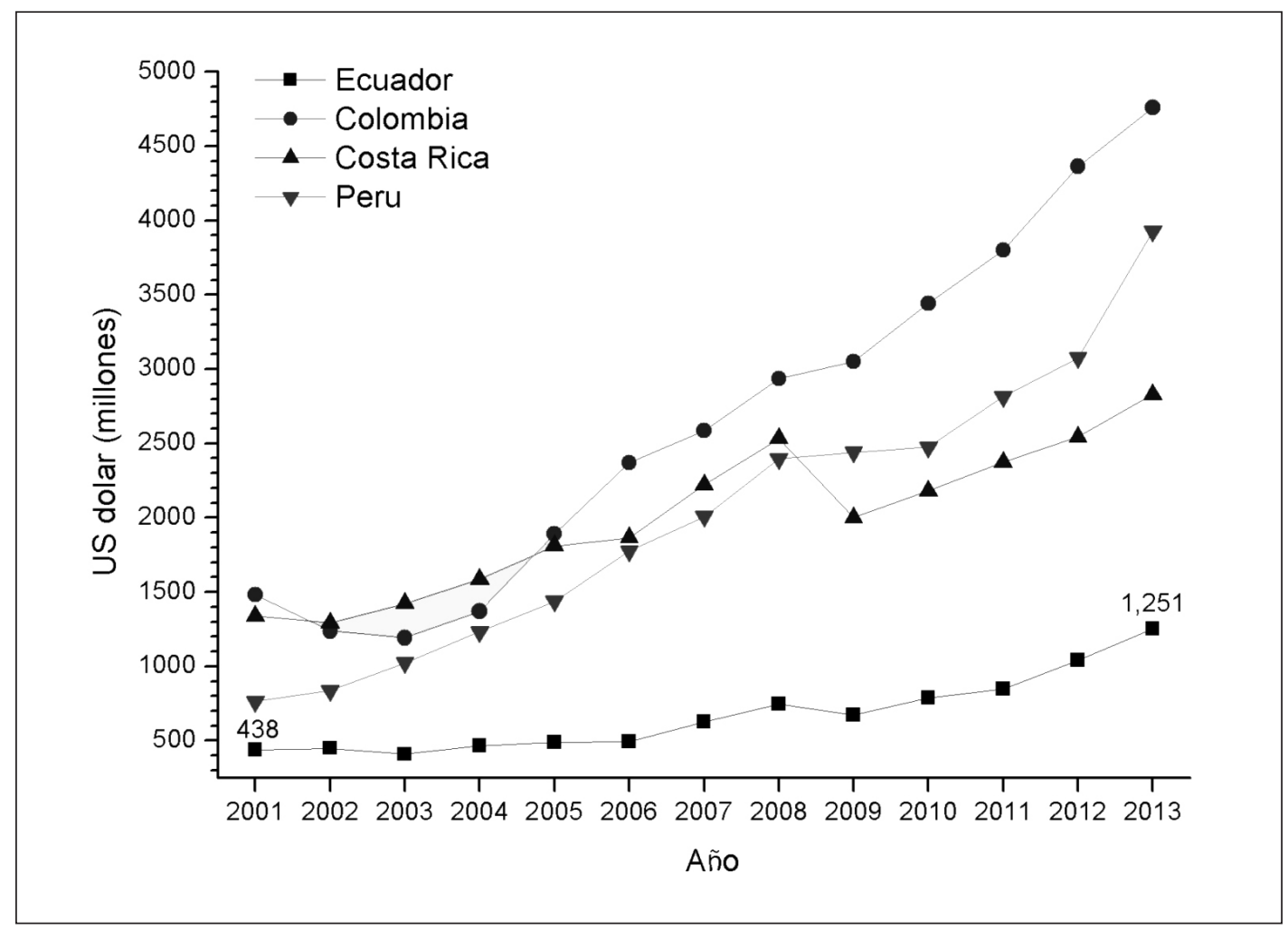

Figura 6. Comparación de ingresos por turismo de Ecuador con países de competencia directa (Fuente: World Development Indicators, 2015).

Los ingresos en la serie presentada se han triplicado, generando un impacto positivo para la economía del país y al cambio de la matriz productiva establecido en el Plan Nacional para el Buen Vivir. Es un sector productivo de suma importancia para la generación de ingresos provenientes del exterior. Sin embargo, como se observa en estos dos cuadros comparativos, el Ecuador ha perdido posición porcentual de los ingresos generados por turismo receptivo, frente a los países escogidos para este balance (Figura 7).

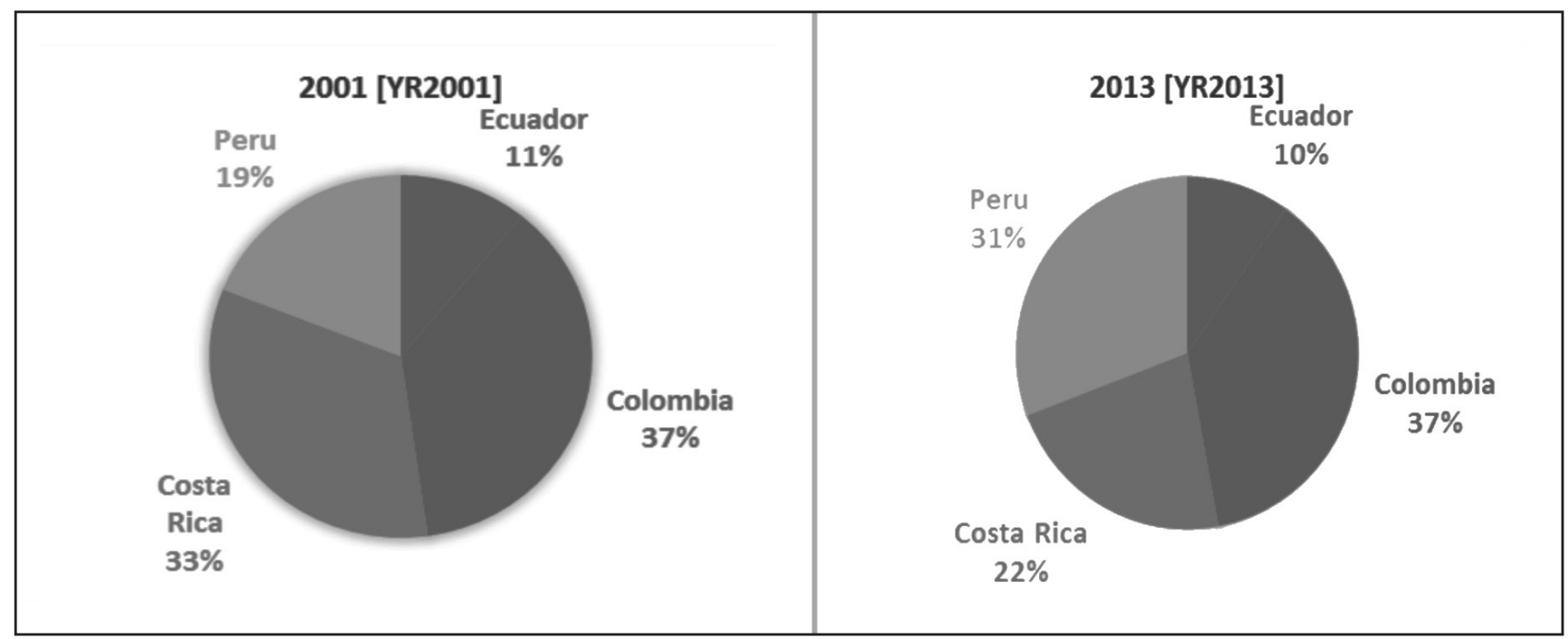

Figura 7. Comparación del market share de los ingresos económicos, con países competencia, del turismo en Ecuador, del 2001 y 2013 (Fuente: World Development Indicators, 2015). 
Se observa que el turismo ocupa un importante puesto en el PIB del país, siendo una excelente opción para la generación de ingresos del exterior. Pero, el turismo ecuatoriano ha perdido porcentaje dentro de la capacidad de captación de divisas por este concepto, frente a mercados competencia.

\subsubsection{Tendencias sobre los ingresos del turismo al 2035 y su impacto en la demanda laboral}

En la Figura 8 se resume cuánto el país recibe por cada visitante del exterior. En la serie se observa que en trece años el ingreso por turista aumento en un $34 \%$, monto de importancia para la economía ecuatoriana. La tasa media de crecimiento de estos ingresos es del 2,61\% y, de mantenerse este incremento, representará para el año 2035 un valor de USD 1.617 por persona. Si contrastamos este valor con el estimado del número de turistas receptivos para el 2035, el ingreso real podría ser de al menos USD 9.002.152.384. Son varios los factores claves para llegar a este escenario, uno de los cuales es el talento humano, considerado por muchos como crucial.

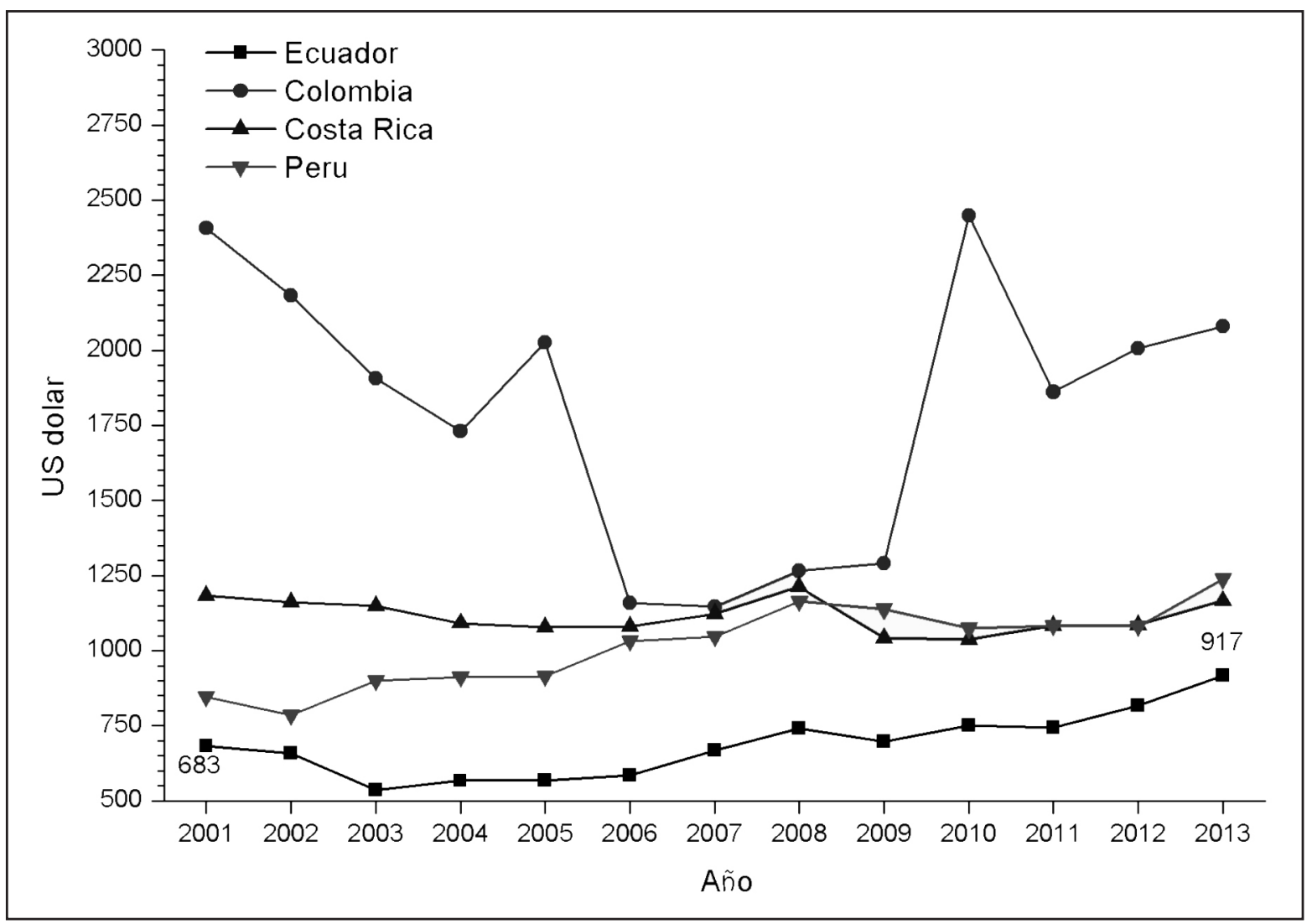

Figura 8. Ingreso económico por turista en Ecuador, comparado con países competencia. (Fuente: World Development Indicators, 2015).

\subsection{Proyecciones de la demanda laboral de acuer- do con el turismo emisivo}

El turismo emisivo ecuatoriano ha mantenido su crecimiento, tal como se observa en la serie presentada en la Figura 9. Si bien Ecuador se mantiene rezagado en comparación a sus mercados competidores, el crecimiento del turismo emisivo ha sido transcendental para mantener una balanza turística que en muchos años del período evaluado ha sido negativa. Este crecimiento responde también a otros procesos como la migración a otros países y la facilidad de ir a destinos lejanos que antes eran muy costosos. Mucho del recurso humano de agencias de viajes tienen mayor conocimiento y facilidad a vender destinos en el exterior, sobre los lugares turísticos del país. 


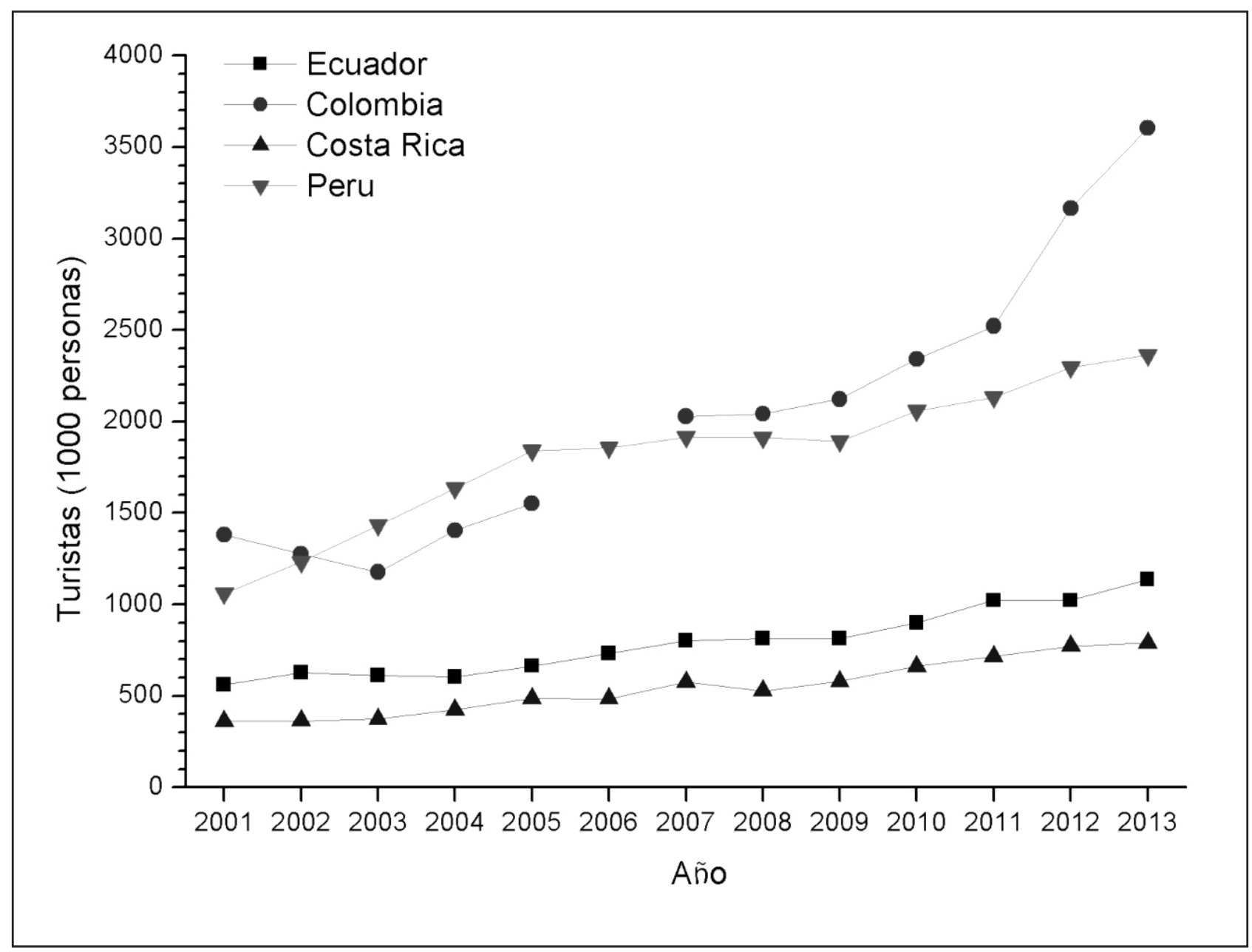

Figura 9. Evolución del turismo emisivo del Ecuador comparado con países de competencia directa (Fuente: World Development Indicators, 2015).

Se observa que el turismo emisor crece de forma sostenida, aunque muchas de las salidas son de migrantes que luego no retornan al país. El turismo ecuatoriano tiene una balanza de pagos inestable, muchas veces los egresos por el turismo emisivo ha superado al receptivo.

\subsubsection{Tendencia del turismo emisivo ecuatoriano al 2035 y su relevancia en la demanda laboral}

La tasa de crecimiento promedio es de 6,78 $\%$. Si se mantiene este ritmo para el 2035 el turismo emisivo será de 4.818 .595 personas en un año. Es de mucha importancia contrarrestar el crecimiento excesivo del emisivo, fomentando el turismo interno, para fortalecer la endeble balanza de pagos en turismo. Una razón más por la cual la calidad y pertenencia del talento humano formado en la universidad será clave para la consecución de estas metas.

\subsection{Proyecciones de la demanda laboral de acuerdo con el turismo interno}

El turismo interno es el otro elemento de importancia en el turismo ecuatoriano. Manteniendo los porcentajes obtenidos del estudio de la cuenta satelital del turismo, que mencionan que el turismo de los ecuatorianos en el país representa al 55\% del valor total del número de personas que se han desplazado en el país, hacia el país y desde el país (Figura 10). Este valor estimado para el 2015 sería de 3.379.725 personas. 


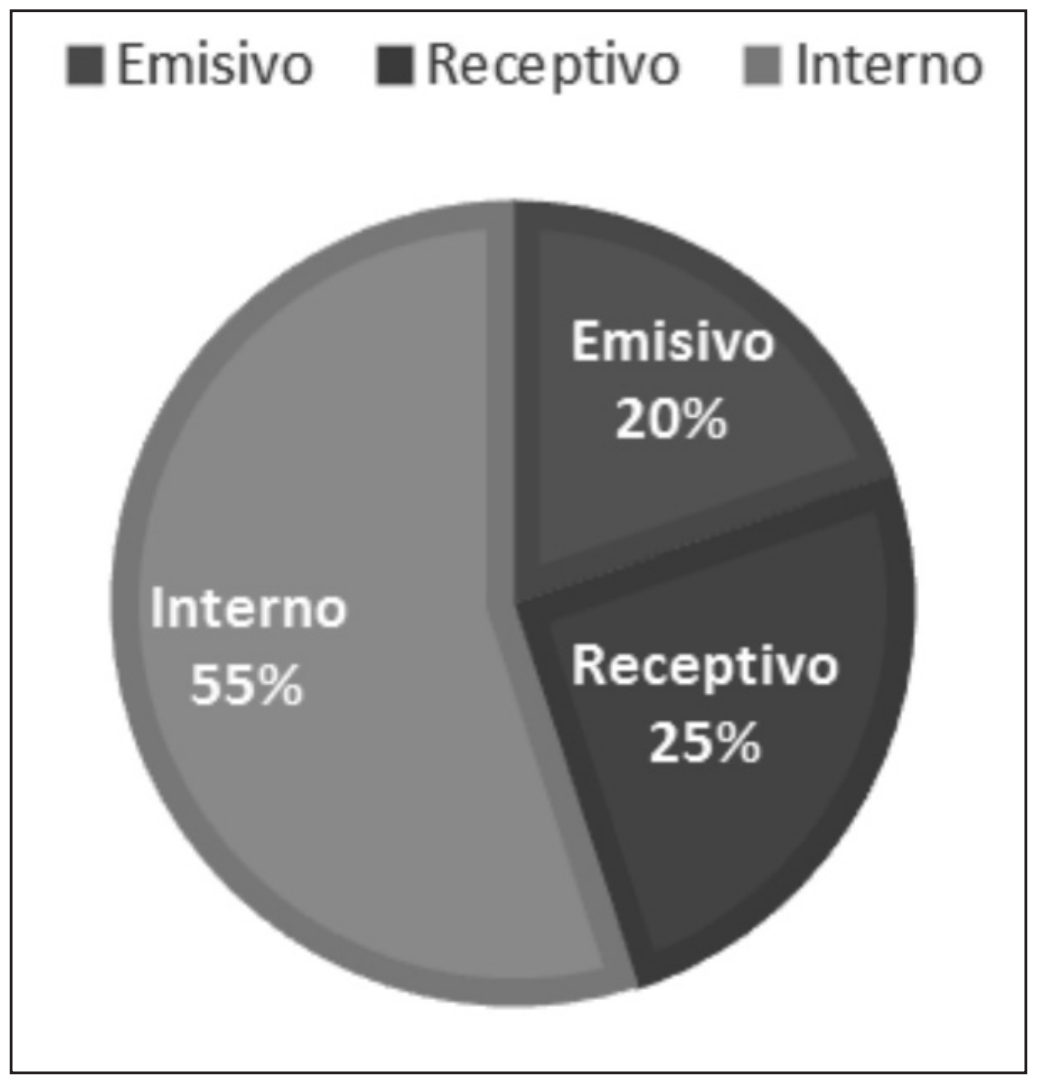

Figura 10. Composición del market share del turismo ecuatoriano según destino de viaje (Fuente: Marconi \& Falconí, 2005).

El turismo interno ha aumentado en número, cantidad de días, montos de gastos en los últimos años, sin embargo, no ha logrado consolidar nuevos destinos y mayormente ha utilizado aquellos que se consideran como clásicos en el trade turístico. La ausencia de personal capacitado para promocionar y comercializar el país ha debilitado el crecimiento de nuevos destinos potenciales y no ha logrado combatir el viaje emisivo de un sector de la ciudadanía.

El turismo interno es un eje para la redistribución de riquezas en todo el país. Según varios reportes de prensa y del mismo ministerio su crecimiento es considerable y continuo. Con este crecimiento se han fortalecido los segmentos de sol y playa, pero han surgido otros con fuerza como el de aventura, ecoturismo, de salud, religioso, entre otros. Por algunas mediciones locales se puede afirmar que el número estimado con base en los datos del Ministerio de Turismo es aún muy conservador.
3.4.1. Tendencia de desarrollo del turismo interno ecuatoriano al 2035 y su impacto en la demanda laboral

Los ecuatorianos ven a su país como un lugar para vacacionar. Han mirado a la vez posibilidades que no sean solo de sol y playa (nicho más demandado), sino que actualmente hay un flujo considerable a la Amazonía, al austro ecuatoriano y a lugares con intereses específicos como de aventura, ornitología, entre otros. Es por esta razón que la demanda de profesionales de turismo se ha incrementado en los destinos emergentes, al igual que en aquellos que han ido posicionándose $\mathrm{y}$ fortaleciéndose.

\subsection{El turismo, un sector con una considerable demanda insatisfecha de profesionales}

La demanda de profesionales formados en turismo en el Ecuador tiene varias entradas, tal como se observa en la Tabla 1. 
Tabla 1. Resumen de demanda laboral turística en el Ecuador.

\begin{tabular}{|c|c|c|c|}
\hline Tipo de ocupación & Mercado laboral & Número aproximado & Estado de satisfacción \\
\hline $\begin{array}{l}\text { Equipo de trabajo espe- } \\
\text { cializado en planificación } \\
\text { turística para GAD parro- } \\
\text { quiales, cantonales, provin- } \\
\text { ciales, nacionales. }\end{array}$ & $\begin{array}{l}\text { Parroquias: } 1.129 \text {, con equi- } \\
\text { pos de al menos } 2 \text { personas. } \\
\text { Cantones: } 221 \text { con equipos de } \\
\text { por lo menos } 4 \text { personas. } \\
\text { Provincias: } 24 \text { con equipos de } \\
\text { al menos } 8 \text { personas. } \\
\text { Ministerio de Turismo: a nivel } \\
\text { nacional } \\
\text { Otras instituciones públicas: } \\
\text { por lo menos otras } 10 \text { insti- } \\
\text { tuciones públicas tienen al } \\
\text { menos un equipo con dos } \\
\text { especialistas en turismo. }\end{array}$ & $\begin{array}{l}\text { Parroquias: } \\
2.258 \text { personas. } \\
\text { Cantones: } \\
884 \text { personas. } \\
\text { Provincias: } \\
192 \text { personas. } \\
\text { Ministerio de Turismo: } \\
614 \text { personas. } \\
\text { Otras instituciones públicas: } \\
20 \text { personas }\end{array}$ & $\begin{array}{l}\text { BAJO: De los sondeos rea- } \\
\text { lizados, en los gobiernos } \\
\text { autónomos, se ha identifi- } \\
\text { cado que son muy pocos los } \\
\text { profesionales graduados en } \\
\text { turismo o carreras relacio- } \\
\text { nadas que trabajan en es- } \\
\text { tas áreas. De forma similar } \\
\text { acontece en el Ministerio de } \\
\text { Turismo y en otras institu- } \\
\text { ciones del Gobierno central. }\end{array}$ \\
\hline $\begin{array}{l}\text { Empresas privadas } \\
\text { del Ecuador: }\end{array}$ & $\begin{array}{l}\text { Agencias de viajes: } 1.554 \text { con } \\
\text { un promedio de al menos } 3 \\
\text { personas por empresa. } \\
\text { Alojamiento: } 4.047 \text { empresas } \\
\text { con un promedio de al menos } \\
5 \text { personas. } \\
\text { Comidas y bebidas: } 12.437 \\
\text { con un promedio de al menos } \\
4 \text { personas por empresa. } \\
\text { Recreación, diversión, espar- } \\
\text { cimiento: } 759 \text { con un prome- } \\
\text { dio de al menos } 5 \text { personas por } \\
\text { empresa. } \\
\text { Transporte turistico: } 369 \text { al } \\
\text { menos } 3 \text { personas por empresa }\end{array}$ & $\begin{array}{l}\text { Agencias de viaje: } \\
4.662 \text { personas } \\
\text { Alojamiento: } \\
20.235 \text { personas. } \\
\text { Comidas y bebidas: } \\
49.748 \text { personas. } \\
\text { Recreación, diversión, } \\
\text { esparcimiento: } \\
3.795 \text { personas. } \\
\text { Transporte turístico: } \\
1.107 \text { personas. }\end{array}$ & $\begin{array}{l}M E D I O \text { : del sondeo que se } \\
\text { realizó la ocupación de per- } \\
\text { sonal graduado en turismo y } \\
\text { carreras afines es interme- } \\
\text { dia. Especialmente en los } \\
\text { mandos medios y directivos } \\
\text { hay variedad de profesio- } \\
\text { nales de otras carreras, con } \\
\text { poca o nula experticia en el } \\
\text { sector. }\end{array}$ \\
\hline $\begin{array}{c}\text { Organismos } \\
\text { no gubernamentales }\end{array}$ & $\begin{array}{l}\text { Tomando como referencia un } \\
\text { estudio de ONG que apoyan al } \\
\text { turismo comunitario se obser- } \\
\text { van más de } 50 \text { a nivel nacional } \\
\text { e internacional que trabajan } \\
\text { en el país: mínimo } 2 \text { personas } \\
\text { por equipo. }\end{array}$ & ONG: 100 personas & $\begin{array}{l}\text { BAJO: del sondeo aplicado } \\
\text { se observó que en las ONG } \\
\text { los encargados de proyectos } \\
\text { de turismo, son, en muchas } \\
\text { ocasiones, profesionales que } \\
\text { no tiene una carrera relacio- } \\
\text { nada con el sector. }\end{array}$ \\
\hline Consultores & $\begin{array}{l}\text { Número indeterminado, sin } \\
\text { registro. }\end{array}$ & $\begin{array}{l}\text { Consultores: } 20 \text { personas } \\
\text { (aproximado de acuerdo con } \\
\text { el número de empresas espe- } \\
\text { cializadas que concursan en } \\
\text { compras públicas) }\end{array}$ & $\begin{array}{l}\text { MEDIO: del sondeo se } \\
\text { observó que muchos de } \\
\text { los consultores en turismo } \\
\text { provienen de otras carreras, } \\
\text { aunque el porcentaje está en } \\
\text { el nivel medio pues por te- } \\
\text { mas de competitividad con } \\
\text { otras consultoras se privile- } \\
\text { gia a aquellos con estudios } \\
\text { en el sector. }\end{array}$ \\
\hline
\end{tabular}

Como se observa en la Tabla 2 hay un total aproximado de 83.635 puestos de trabajo para profesionales de turismo. Tomando en cuenta la siguiente matriz y considerando que todos los graduados en turismo estén laborando directamente en el área, el porcentaje de demanda satisfecha es de apenas el $55 \%$ de los empleos directos creados en el sector. Es decir, en el mejor de los escenarios, 1 de cada 2 profesionales del sector turístico no tienen un título relacionado con el área. 
Tabla 2. Títulos en turismo, gastronomía, hotelería y restaurant (tercer nivel).

\begin{tabular}{|c|c|c|c|c|}
\hline & Turismo & Gastronomía & Hotelería & Restaurant \\
\hline Total & 26.151 & 3.734 & 15.861 & 43 \\
\hline Antes de 2004 & 4.188 & 58 & 2.136 & 8 \\
\hline 2004 & 843 & 40 & 478 & 1 \\
\hline 2005 & 1.119 & 68 & 715 & . \\
\hline 2006 & 1.343 & 92 & 819 & 1 \\
\hline 2007 & 1.831 & 109 & 1.137 & 2 \\
\hline 2008 & 1.806 & 195 & 1.071 & 2 \\
\hline 2009 & 2.483 & 198 & 1.750 & 2 \\
\hline 2010 & 2.097 & 255 & 1.233 & . \\
\hline 2011 & 2.174 & 335 & 1.423 & 1 \\
\hline 2012 & 1.752 & 506 & 1.024 & 2 \\
\hline 2013 & 2.383 & 737 & 1.327 & 3 \\
\hline 2014 & 1.547 & 570 & 897 & 7 \\
\hline 2015 & 1.844 & 565 & 1.047 & 14 \\
\hline No Registra & 741 & 6 & 804 & . \\
\hline
\end{tabular}

Tomando en cuenta el crecimiento sostenido del sector y, que, en palabras del Ministerio de Turismo, el empleo directo e indirecto al 2014 fue de 344.800 puestos de trabajo, considerando igual presunción que en el caso anterior, de un escenario en el cual TODOS los graduados de turismo estén laborando en el sector la demanda satisfecha sería tan solo de un $13 \%$. Queda totalmente demostrado que el sector turístico tiene una alta empleabilidad, por lo que carreras de calidad en el sector son estratégicas dentro del Plan de Desarrollo para el Buen Vivir y del Plan de Cambio de la Matriz Productiva del Ecuador. Nueve empleos directos e indirectos del turismo, no son ocupados por una persona con formación universitaria.

\section{Conclusiones}

El país tiene un retroceso en sus proyecciones de crecimiento turístico, que aún son más notables si las comparamos con países de competencia directa como son Colombia, Perú y Costa Rica. Este estancamiento se debe a varios factores, pero uno de ellos es la insuficiencia de un talento humano formado para el trabajo, el emprendimiento y la innovación en el sector turístico. La falta de consolidación de destinos o la incorrecta gestión turística en los municipios, cantones y provincias, son bases para no haber crecido como estuvo previsto en el PLANDETUR 2020, todo lo cual está directamente relacionado con las personas que deben hacer esas tareas.

La fuerza laboral del turismo en Ecuador está ocupada por personas de otras profesiones y mayormente por individuos con competencias básicas (idioma, ofimática) que han sido contratados para llenar las plazas requeridas por los diferentes empleadores, tanto públicos, privados, no gubernamentales y comunitarios, ante la falta de personal capacitado de forma adecuada. Esto ha producido cierto distanciamiento entre la empresa y 
los centros de educación superior, puesto que expresa que las instituciones educativas no cubren la demanda y en algunos casos las competencias no están actualizadas. Para el caso del Estado las contrataciones tienen más de afinidad política que de personas con las capacidades necesarias para la gestión turísticas de estos territorios.

Quedan abiertos innumerables líneas de investigación sobre este tema como: la relación academiaempresa (pública, privadas, comunitarias, no gubernamentales, etc.) en la formación integral del talento humano del sector turístico; el estado del talento humano en los puestos laborales; los procesos de capacitación y actualización profesional del sector, entre muchos otros temas que deben ser abarcados sobre el talento humano y su proceso educativo.

\section{Referencias}

Banco Mundial. (2015). Indicadores de desarrollo mundial. Recuperado de: http://data.worldbank. org/data-catalog/world-development-indicators

Cabanilla, E. (2016). La configuración socio-espacial del turismo comunitario, caso República del Ecuador. Tesis doctoral. Avance no publicado. Argentina: Universidad Nacional del Sur.

Marconi, S. \& Falconí, J. (2005). Una interpretación mesoeconómica del turismo en Ecuador. Quito: Banco Central del Ecuador

Ministerio de Turismo del Ecuador. (2007). Plan estratégico de desarrollo del turismo sostenible en Ecuador hacia el año 2020: PLANDETUR 2020. Quito: Ministerio de Turismo del Ecuador.

Ministerio de Turismo del Ecuador. (2014). La gráfica de la campaña 'All You Need Is Ecuador' ganó premio en Alemania.
Finalmente, según los datos proporcionados por el Ministerio de Turismo (ente rector del sector en el país), la brecha es muy significativa, pues tan solo el 10\% de los empleos directos o indirectos generados por el sector turístico pudieran estar cubiertos por profesionales graduados de las instituciones de educación superior del país. Sin rechazar la posibilidad de que profesionales de otras disciplinas, interconectadas con el turismo, pudieran ser parte del talento humano del turismo, queda demostrado que existe aún una demanda insatisfecha actual muy importante, que con las proyecciones realizadas será aún más significativa en el futuro. Estas son suficiente razones para fortalecer y auspiciar los estudios de turismo a nivel nacional.

Recuperado de: http://www.turismo.gob.ec/lagrafica-de-la-campana-all-you-need-is-ecuador-gano-premio-en-alemania/

Ministerio de Turismo del Ecuador. (2015). Noticias sobre demanda laboral sector turismo Ecuador. Recuperado de http://www.turismo.gob.ec/ministerio-de-turismo-busca-duplicar-el-numero-de-ingreso-de-visitantesalcanzada-en-el-2006/

Ministerio de Turismo del Ecuador. (2015). Catastro de servicios turísticos del Ecuador al 2013. Quito: Ministerio de Turismo del Ecuador.

Secretaría de Educación Superior, Ciencia, Tecnología e Innovación (SENESCYT). (2015). Histórico de graduaciones en el sector turismo, gastronomía, hotelería y restaurante. Documento no publicado. 